\title{
A Legitimação Adotiva, Forma Mais Avançada de Integração de Crianças Abandonadas ou Expostas, em Lares Substitutos. Diferenças, Inconvenientes e Vantagens com Referência à Adoção*.
}

\author{
Antônio Chaves \\ Catedrático de Direito Civil na Faculdade de \\ Direito da Universidade de São Paulo.
}

Sinto-me desvanecido, senhor Diretor, com o convite de V. Excia. para ministrar esta aula inaugural.

A distinção, se é sempre generosa, adquire, no meu caso, particular significação, pois estabelece uma reaproximação com antigos e queridos amigos e companheiros de ideal, relacionando assim intensas vibrações atuais com felizes vibrações pretéritas, que durante cinco anos, pelo contacto diuturno com colegas do magistério, da magistratura, do Ministério Público, com advogados e então... futuros advogados, acalentaram meu coração.

Trazido que fui por êsse cidadão admirável que é Costa E Silva, permiti que nele reverencie todos os professôres desta Casa. Varão de Plutarco, às lições de seu curso, por sua natureza efêmeras, por mais perfeitas que sejam, aditou uma imperecivel, que é a do exemplo de uma alma varonil que não se deixa intimidar e muito menos dobrar pelas adversidades do destino.

1. Aula inaugural do ano letivo da Faculdade de Direito de Santos, proferida em 4-3-1966. 
Um digno continuador de sua obra teve no entanto a ventura de encontrar esta Faculdade em Vossa Excelência, Doutor Carlos Pacheco Cyrillo, que com energia, descortino e vigilância, às glórias passadas novas consagrações vem sempre acrescendo.

Não poderia corresponder a sentimentos tão elevados senão procurando um tema digno de uma cidade nobre e generosa como a de Santos, que tanto se tem distinguido no trato do problema das crianças desamparadas.

Recaíu a escolha na legitimação adotiva, um dos rebentos mais novos do Direito de Família, a revelar a inquietação e as tendências do legislador moderno, que já não se contenta mais de proporcionar a tais infelizes os meios necessários para a própria subsistência e criação, o que é apenas caridade. Procura, vencendo antigos escrúpulos e preconceitos, corrigir as próprias asperezas de uma sorte adversa, fazendo com que êstes pequeninos sêres, que não têm culpa dos erros ou dos pecados de seus pais, e que não podem ser punidos pela fatalidade que os acometeu, encontrem a redenção de um lar substituto.

Permitindo singelamente voltem aquêles que estariam impedidos pela natureza cega e insensível de articular duas pequenas, mas enternecedoras palavras, que em si resumem tôda a humanidade: "mamãe", "papai", presta o legislador a sua colaboração para que se realize o suave milagre de recompor uma existência, que de outra forma estaria irremediàvelmente truncada e comprometida.

Isto, senhores, já não é mais caridade apenas, é compreensão verdadeiramente cristã da lição Daquele que queria que deixassem ir a Êle os pequeninos.

\section{A adoção na história e na literatura.}

Não me permite o dever de não abusar da paciência dos meus caros ouvintes dissertar a respeito da adoção, tema como que introdutório do que vou abordar. 
Mas algumas referências facilitarão a compreensão da matéria, tanto mais quanto, na história e na literatura, exemplos sem conta poderiam ser invocados, ou de situações muito semelhantes à da adoção, ou de adoções pròpriamente ditas.

Conhecida e praticada desde a mais remota antigüidade, com finalidades religiosas, políticas e econômicas, a adoção teve uma regulamentação minuciosa e avançadíssima no Código de Hammurabi, 2.283 - 2.241 anos antes de Cristo, e foi amplamente praticada na Mesopotâmia, em Atenas, no Egito.

São numerosos os testemunhos bíblicos: Efraim e Manés foram adotados por Jacó, Ester por Mardoqueu, Moisés por Térmulus, filha do Faraó, José por Potifar.

A realçar-lhe a importância, a história de Roma, e, portanto, da civilização ocidental, começa, simbòlicamente, com a acolhida de Rômulo e Remo por Faustulo e Aca Laurência.

No Lácio a adoção foi estruturada cuidadosamente, com disposições que ainda hoje inspiram o legislador em tôdas as latitudes.

Para dizer do papel relevantíssimo que aí desempenhou, basta lembrar que a seqüência dos imperadores está pontilhada por nomes de filhos adotivos: Scipião Emiliano, Cesar Otaviano, Calígula, Tibério, Nero, Justiniano. No fim da República, Cláudio, para chegar ao tribunato, fêz-se adotar por um plebeu, e Galba adotou Pison, um homem do povo, para que pudesse continuar as tradições do seu govêrno.

$\mathrm{Na}$ história pátria um exemplo edificante nos legou a Imperatriz Dona Amélia, quando, longe de revelar-se madrasta, foi uma verdadeira mãe adotiva, cheia de sensibilidade e ternura, para com os filhos de D. Pedro I e da Imperatriz Leopoldina.

Longe iríamos, se quizéssemos seguir os traços deixados pela adoção em obras de literatura. 
São imortais os versos em que, na Ilíada, Félix lança a Aquileus a dolorosa invocação:

\author{
“...ah! Eu muito, \\ até saíres da penosa infância, \\ sofri contigo, e trabalhei bastante, \\ na doce esperança de que um dia, \\ já que irados os deuses me negavam \\ sucessão, adotando-te como filho, \\ meu amparo e meu consôlo tu serias!"
}

Filho adotivo foi Teseu Hipólito, na tragédia Fedra, de Sófocles.

Quem não se encantou, na infância, com as peripécias de Mowgli, o menino lobo, na genial criação de Kıplıng, a relacionar fatos provàvelmente de fundo verídico, ocorridos na India, com a lenda antípoda da fundação de Roma?

Quem não lembra passagens expressivas do Conde de Monte Cristo, de Alexandre Dumas, de Os Miseráveis, de Vitor Hugo, de Colette, de Affonse Daudet, de Sans Famille, de Hector Mallot, de $O$ Egípcio, de Mika Waltari, quem não se comoveu com o episódio tão bem retratado por Honoré de Balzac, de A missa do Ateu?

\title{
Adoção e estatística.
}

Abandonemos, no entanto, o reino encantado da literatura e da história, para, dos aparentemente áridos domínios da estatística, extrairmos a confortadora expressividade, em números, da adoção no mundo de hoje.

Sòmente nos Estados Unidos da América do Norte, num único ano, no de 1955, foram deferidos 93.000 pedidos de adoção, total êsse que em 1960 subiu para 107.000!

Se considerarmos que além dêsses dados oficiais existe uma imensidade de situações de fato não recenseadas, há 
de se chegar à conclusão de que tôda uma população humana, destinada a padecer uma existência de dificuldades e misérias, graças ao gesto generoso da acolhida em lares substitutos, passa a levar uma vida digna e produtiva, drenando-se assim dos pantanais das sargetas, das cadeias, dos hospitaís e dos hospícios, um sem número de criminosos, doentes e loucos em potencial para transformá-los em cidadãos prestantes!

Uma estatística pela primeira vez levantada a nosso pedido, Cartório por Cartório, por determinação do grande ex-Juiz de Menores de Santos e de São Paulo, Aldo de Assis Dias, revela que apenas na capital de São Paulo, de 1955 e 1964 foram levadas a efeito 2.966 adoções, das quais mais da metade contou com a participação direta do Juizado de Menores.

É pouco, certamente, considerando a índole generosa e compassiva do povo brasileiro, mas é um índice expressivo do que poderia ser conseguido através de uma campanha vigorosa e de um auxilio efetivo por parte dos governantes.

\section{0 desdobramento natural da adoção: a legitimação adotiva.}

Mas a adoção, por mais generosa que seja sua finalidade, ainda não satisfaz completamente às exigências do nosso tempo, principalmente pelas hesitações do legislador no que diz respeito à solução de vários problemas: o do nome, o da persistência da vinculação com a família de sangue, a levantar o espantalho sempre presente de futuras reivindicações, o da sucessão hereditária, pràticamente negada ao filho adotivo.

Sòmente a legitimação adotiva veio resolver o problema, tão bem equacionado por Francisco Pereira de Bulhôes Carvalho, dos menores abandonados, que não podiam ser incorporados definitivamente como filhos, pela 
família que os desejasse adotar, "a não ser pelo meio fraudulento e criminoso de fazer declarar como filhos legítimos, atribuindo-lhes falsa qualidade e ainda dando margem à futura anulação do registro por parte dos verdadeiros pais, que tenham antes abandonado os filhos, criando para êstes uma situação social e moral inteiramente injustificável".

O projeto de lei n. 562, apresentado à Câmara dos Deputados em 1955 por Jaeder Albergária, após uma longa elaboração transformado na Lei 4.655, de 2-6-1965, deu ao nosso país a glória de ter sido o segundo no mundo inteiro, a seguir a senda traçada pelo legislador francês, insculpindo em sua legislação, uma das mais brilhantes conquistas.

Conceito de legitimação adotiva. Relações e diferenças com a adoção.

Trata-se de instituto completamente diferente da legitimação, e, ao mesmo passo, bem distanciado da adoção, pois seus efeitos são mais profundos e duradouros.

Podemos definir a legitimação adotiva como a outorga judicial, de efeitos constitutivos e com as condições de segrêdo, irrevogabilidade e total desligamento da família de sangue, obedecidos os requisitos fixados em lei, a um menor até sete anos de idade, abandonado, órfão ou desamparado, do estado de filho legítimo de um casal, excepcionalmente de pessoa viúva, com ressalva dos impedimentos matrimoniais e do direito de sucessão se concorrer com filho legítimo superveniente.

Tivemos, em monografia dedicada ao assunto, oportunidade de encarecer que a adoção é a convocação de um estranho, que tanto pode ser um menor, como um homem ou uma mulher, mesmo casados, para dentro de uma família, ou ao lado de uma pessoa que tenha dezesseis 
anos mais, sem a preocupação de apagar a lembrança ea condição de estranho, ao passo que a legitimação adotiva é a integração, de uma criança, exclusivamente, numa família, e com a preocupação primordial de fazer esquecer por completo a condição de estranho.

É a legalização do parto suposto, eliminando o sentido de infração, para revestí-lo de tốda a luminosidade e o calor de sua significação humana, muito embora não tenha sido o fato explicitamente admitido, como teve coragem de fazer o legislador uruguaio.

A adoção ainda se opera, entre nós, mediante simples. escritura pública, sem a intervenção de qualquer autoridade, sem maiores exigências relativas a documentos; a legitimação adotiva requer um processo especial perante a autoridade judiciária, apresentação de uma série de provas e realização de diligências, com recurso de efeito. suspensivo para o Tribunal de Justiça.

A primeira tanto se admite com relação a maiores como a menores, ao passo que a segunda restringe-se não. apenas a crianças até sete anos de idade, mas ainda, que sejam expostas, abandonadas, ou se encontrem em posição. equivalente.

Aquela pode ser feita por pessoas de qualquer estado civil; esta, em regra, apenas por casais com cinco anos de matrimônio, devendo pelo menos um dos cônjuges ter mais de trinta anos de idade, sem filhos legitimos, legitimados ou naturais reconhecidos.

$\mathrm{Na}$ primeira não se cogita, ao contrário da segunda, das conveniências, do bem estar e do futuro do menor.

Naquela não é aconselhável o segrêdo; nesta, mantê-lo. é tão importante que sua violação sujeita o responsável a penalidades severas.

$\mathrm{Na}$ adoção o vínculo não se estende, pelo menos teòricamente, aos demais membros da família do adotante; na legitimação adotiva é prevista sua extensibilidade. 
$\mathrm{Na}$ adoção permanecem vínculos com a família de origem, e, portanto, a possibilidade de conservar o nome, de suceder, de pedir e de prestar alimentos, o que não acontece com a legitimação adotiva.

Lá é permitida uma grande variedade de composições de nomes e não se admite a modificação do prenome; aqui confere-se ao menor o nome do legitimante ativo, autorizando-se até mesmo, para mais completa integração, a modificação do prenome.

Finalmente, a legitimação adotiva, ao contrário da adoção, é irrevogável, dá lugar, para usar as expressões de Bartolomeu Busi, a um "estado permanente, perpétuo e imutável".

\section{Inconvenientes e vantagens da legitimação adotiva.}

É importante insistir em que a finalidade da legitimação adotiva é estabelecer entre a criança acolhida no novo lar e seus protetores, vínculos mais fortes do que os resultantes da simples adoção.

Os problemas do nome, do direito sucessório, do segrêdo a ser mantido, devem, na adoção, ser resolvidos tendo em consideração a existência da família de sangue, mas na legitimação adotiva têm de seguir critério diferente, para não incorrer no êrro introduzido pelo Senado no art. $9 .^{\circ}$ da Lei n. 4.655, ao eliminar o direito de sucessão caso concorra o legitimado adotivo com filho legítimo superveniente, e mandando aplicar o art. $1605, \S 2 .^{\circ}$ do Código Civil, princípio que só se concebe possa valer com relação à adoção.

Alega-se que, implicando na publicidade da inexistência do vínculo de sangue com a família originária, a legitimação adotiva pode ocasionar prejuízo, quando menos seja, o psicológico dessa revelação, erigindo, em última 
instância, em instituição jurídica, lícita e fomentada, a falsidade do estado civil; que, retirando o legitimado adotivo de sua família de sangue, podem-se-lhe ocasionar prejuízo, por exemplo, em matéria sucessória. Invoca-se ainda a posição dos parentes do legitimante, que, sem seu consentimento, veriam insinuar-se um elemento estranho na família, preterindo eventuais direitos sucessórios. Surgiria, finalmente, a situação vexatória decorrente da não aparência de impedimentos matrimoniais na realidade existentes.

Inconvenientes e imperfeições existem, sem dúvida, como em tôda criação humana. Mas a maioria é decorrente mais de uma situação de fato, que provàvelmente ocorreria independentemente da existência ou não da providência legal.

Mas as vantagens porém sobrepujam, de muito, as deficiências.

Reconhecem-no mesmo aquêles que não manifestam simpatia pelo instituto, como Coll e Estivill, ao admitirem que "alcança o máximo de perfeição: identifica-se ao criado como filho com o próprio filho, não só jurídica, mas psicológica e socialmente; e eliminam-se todos os difíceis problemas emergentes do conflito entre a filiação de sangue e a criada pelo ato jurídico, tanto no pátrio poder, como no nome e nos direitos sucessórios".

$\mathrm{E}$ acabam proclamando que os eventuais prejuízos, sob o ponto de vista legislativo, podem ser postos de lado, ante o conjunto geral de problemas e interêsses que a lei resolve.

A verdade é que os benefícios que a legitimação adotiva pode proporcionar são enormes.

Para lembrar apenas dois dos mais importantes: assimila completamente o filho legitimado por adoção a um filho legitimo; longe de fomentar a falsificação do registro 
civil, evita-a, pois não se poderá qualificar como falsificação um ato praticado mediante autorização legal.

Sugestões para a reforma da legitimação adotiva.

A Lei 4.655, de 2-6-1965, embora abra desmarcadas possibilidades à solução do problema da criança abandonada, aliviando enormemente a tarefa imposta até há pouco. à adoção, cria novos problemas.

Antes de mais nada, impõe uma reformulação completa dos dispositivos relativos à adoção, para que haja um perfeito entrosamento entre êsses dois institutos, por sua natureza complementares, mas que não o são ainda na letra da lei.

Deve ser eliminada a referência contida no art. $1 .^{\circ}$ da Lei 4.655, à possibilidade de alguém $d a r$, por escrito, seus próprios filhos.

A disposição, além de contrária aos mais elementares princípios de dignidade humana, é contraditória com a própria finalidade da legitimação adotiva, em que, diferentemente da adoção, não se exige um acôrdo de vontades do adotante e do adotando, ou do seu representante legal, mas a manifestação por parte do casal legitimante adotivo, de receber uma criança absolutamente incapaz e sem representante, e a outorga por parte do Poder Judiciário, observadas as condições rigorosamente fixadas.

O sistema do "papel passado" subverte por completo a essência do instituto.

Convém admitir, como faz a lei uruguaia, a legitimação adotiva mesmo por parte de casais que já tenham filhos. Não se ponham limites, por falsos preconceitos de ordem material, a impulsos generosos, que possibilitarão a integração de mais sêres abandonados, e companhia para 
muitos filhos únicos, complemento, às vêzes, necessário, para a sua própria criação e educaçao.

Seria conveniente, a exemplo do Código Civil francês, prever a possibilidade de acolher, pela legitimação adotiva, sucessivamente, mais de um filho. A uma criança que assumiu fictìciamente a posição de filho, gozando assim de extraordinário benefício, não se pode arrogar o direito de impedir a repetição de semelhante gesto a favor de outra igualmente desprotegida.

Torna-se necessário texto expresso prevendo a possibilidade de transformar a adoção em legitimação adotiva, o que a lei atual não faculta.

Mesmo que se mantenha o sistema atual com relação à sucessão do filho adotivo, não existe razão plausível para qualquer limitação aos direitos hereditários do legitimado adotivo, ainda que haja concorrência com filhos legítimos anteriores ou posteriores ao ato. Deve ser essa uma das caracteristicas diferenciais, destinada, muitas vêzes, a fazer optar por um ou por outro dos institutos.

Finalmente, exame médico-psiquiátrico do menor, como complemento obrigatório das sindicâncias e diligências a serem procedidas, única maneira de evitar, para pessoas que manifestam disposições altruistas, a surprêsa desagradável de taras e moléstias ocultas, verdadeiras lbombas de efeito retardado.

Perdoai, senhoras e senhores, o abuso cometido contra a vossa paciência e benevolência.

Minha esperança é que tenha contribuido para tornar um pouco mais conhecida a legitimação adotiva.

E o meu sonho é o de que também no Brasil se verifique o sucesso que, segundo informa Raphael Veliounsky, na França, foi "foudroyant", como demonstra a proporção de pedidos: mil e quinhentas legitimações adotivas para oitenta adoções. 
Repetiu ela o mito do aprendiz de feiticeiro: considerada a princípio de importância secundária frente à adoção, não tardou em sobrepujá-la, constatando-se que justamente as crianças abandonadas constituíam a maior parte dos candidatos à adoção, e que, por outro lado, o novo instituto, oferecendo crianças sem família e sem recordações, lisongeava o sentimento mais natural dos adotantes: uma ficção acrescida de paternidade. 